\title{
Burden of road traffic injuries and related risk factors in low and middle-income Pacific Island countries and territories: a systematic review of the scientific literature (TRIP 5)
}

\author{
Josephine Herman ${ }^{*}$, Shanthi Ameratunga and Rod Jackson
}

\begin{abstract}
Background: In Pacific Island countries and territories, the burden of road traffic injuries and their attendant risks are considered significant but are poorly quantified. As with other low and middle-income countries, understanding the epidemiology of road traffic injuries in Pacific countries is critical to informing sustainable research and policy initiatives aimed at reducing this burden.

Methods: We undertook a systematic review and critical appraisal of the relevant epidemiological literature between January 1980 and December 2010, using key search strings for incidence and aetiological studies focusing on RTIs in less resourced Pacific countries.

Results: Nineteen studies were identified. The majority were descriptive and were unable to provide population-based estimates of the burden of road crash injury, or reliable information on risk factors using well-designed aetiological research methods. All studies were published more than 10 years ago, and all but three reported on data from Papua New Guinea, thereby limiting the generalisability of findings to the current status in the region. Studies undertaken in Papua New Guinea suggested that RTls were more frequent among young males, with head injuries the most common cause of death or hospital admission. Two thirds of fatalities occurred th the crash site or soon after admission. Most road crash victims were passengers or pedestrians. Factors postulated to influence the risk of RTIs were travel in open-back utility vehicles, utility vehicle overcrowding, and alcohol.

Conclusions: This review suggests that, despite increasing awareness of the importance of addressing road safety among stakeholders in less resourced Pacific Island countries, road traffic injuries have not been a research priority with little relevant current evidence from the region to inform policy. Robust epidemiological research that can assess the magnitude and key determinants of road traffic injuries in these settings is essential to determine context-specific road safety initiatives that are relevant and affordable. Greater attention to harnessing routinely collected data (e.g., hospital information systems and police crash statistics) to inform policy is also required.
\end{abstract}

\section{Background}

Road traffic injuries (RTIs) are a significant public health challenge and projected to be the fifth leading contributor to the global burden of disease by 2030 [1]. Over $90 \%$ of fatal crashes occur in low and middle-income countries with substantial consequences, particularly for vulnerable road users such as pedestrians, cyclists, and

\footnotetext{
* Correspondence: j.herman@auckland.ac.nz

Section of Epidemiology and Biostatistics, School of Population health, University of Auckland, Private Bag 92019, Auckland, New Zealand
}

riders of motorised two-wheelers [2-4]. In Pacific Island countries and territories, the published literature suggests that RTIs and their attendant risks are a significant but poorly quantified cause of death and disability [5-7]. It has been reported that up to half of all fatal injuries in the Pacific are due to road traffic crashes [8]. Previous commentators and researchers have also drawn attention to the impact of RTIs among Pacific populations, highlighting factors that require particular attention such as alcohol, motorisation, poor driving, seatbelt use, and poorly maintained vehicles and roads [9-15]. The Global

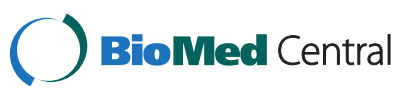


road safety survey identifies Pacific Island countryspecific characteristics from the perspectives of government statistics and stakeholders [16]. However in order to develop effective road safety initiatives that are relevant for the Pacific context, it is important to assess the quality of local research evidence examining the burden and risk factors for road crashes, and gain a broader appreciation of its utility to influence national policy and behavioural change [17-19]. To this end, we undertook a systematic review of the published literature of epidemiological studies investigating the burden of and modifiable risk factors for RTIs in less resourced Pacific countries.

\section{Methods}

We identified and critically appraised epidemiological studies published between January 1980 and December 2010 focusing on RTIs. The countries of interest comprised 18 of the 22 member states of the Secretariat of the Pacific Community, encompassing all of the countries in the Pacific region but excluding high-income countries as classified by The World Bank [20]. Studies describing the burden of RTIs were included if they presented epidemiological data on road users who had sustained an injury as a result of a road traffic crash. Studies investigating risk factors for RTI were reviewed if they included a comparison group or time period (as in case crossover studies) with respect to the exposure of interest, and the study outcome measure was a road traffic crash resulting in an injury (fatal or non-fatal). Therefore the primary study designs of relevance included: case control, cohort, case crossover, or cross sectional research methodologies. The following electronic databases were searched building on strategies recommended for reviewing the literature addressing incidence and aetiological studies [21]: Medline, EMBASE, CINAHL, PsycINFO and the Australian Transport and Road Index database, and Transport Research International Documentation. A search string applied for the review is provided in additional material. (Additional file 1). The keywords and relevant medical subject heading terms used included: specific names of all eligible Pacific Island countries and territories, Polynesia, Melanesia, Micronesia, Oceania, road user, driver, occupant, passenger, pedestrian, motor, vehicle, cycle, bike, moped, automobile, car, walking, traffic, road, accident, crash, collision, casualty, trauma, wound, injury, fatal, death, disability. Specific search terms for risk factors included alcohol, wine, spirit, beer, seatbelt, helmet, head protective device, sleep, fatigue, apnoea, conspicuity, visibility, illumination, visual, headlights, light, colour, contrast. Further studies, reports, conference proceedings, and other relevant publications in the grey literature were located through the reference lists of identified articles and websites of groups involved in injury and Pacific health research. In addition, we undertook hand and electronic searches of the PNG MED J (1972-2009), Fiji Medical Journal (1974 - October 2006), and Pacific Health Dialogue (1994-2010), as well as journals with a focus on injury, specifically Accident Analysis and Prevention, Injury, Injury prevention, Journal of Injury Control and Safety Promotion, Journal of Safety Research, and Traffic Injury Prevention.

The review was restricted to studies published in the English language. All studies identified were screened initially by title and abstract, and then more thoroughly in full text. (Figure 1) Adhering to PRISMA guidelines,1 (Additional file 2) studies meeting the inclusion criteria

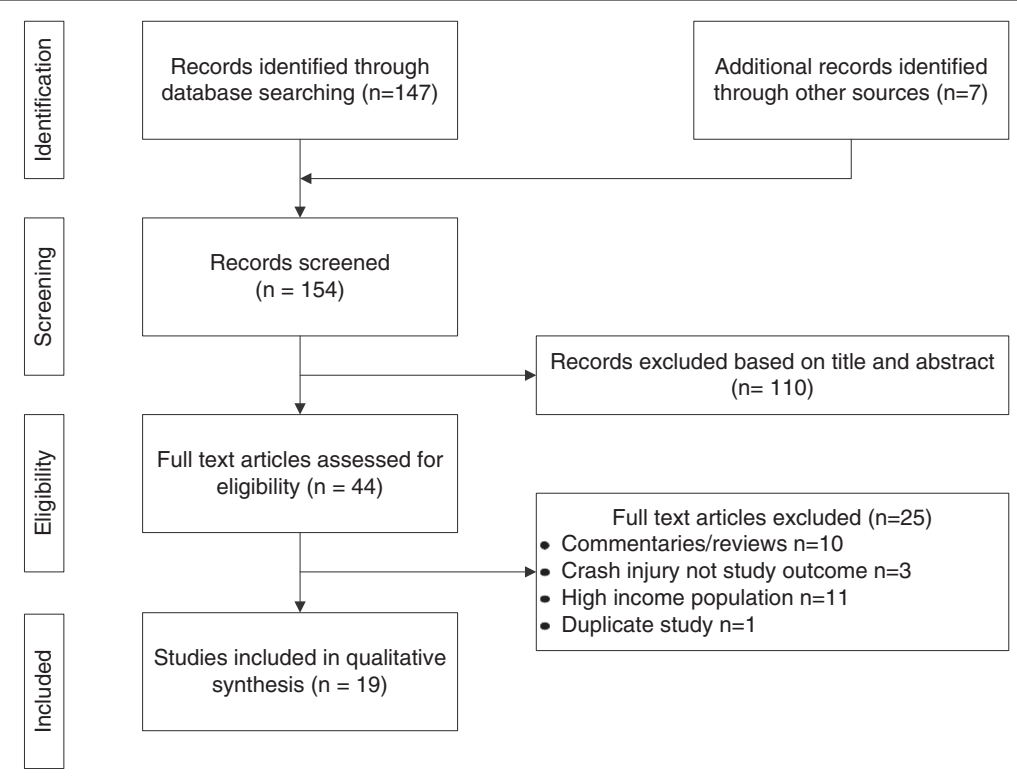

Figure 1 Flow diagram of studies selected for review. 
were critically appraised for the quality of the evidence using GATE-LITE ${ }^{\mathrm{mix}}$ [22] and summarised in evidence tables with the following headings: study design, participants, variables examined, key findings relevant to the review and study appraisal and comments. (Table 1).

\section{Results}

Nineteen studies [23-41] published between 1980 and 2010 met the inclusion criteria with the most recent RTIspecific study published in 1996 [41]. One study was published in two journals $[41,42]$, so the study with less information was excluded [42]. Fifteen studies were case series; including ten studies identifying cases from retrospective records [23-26,28,29,31,32,35,37], three studies from prospective records $[27,30,36]$, and two studies from both retrospective and prospective records [33,34]. There were three ecological studies [38-40], and one study was a case control study [41]. All but three studies were undertaken in Papua New Guinea (PNG), the exceptions being retrospective case series conducted in Yap [35], and the Republic of Fiji (Fiji) [31,37]. Eleven studies focused on describing the overall burden of RTIs and type of road users injured [23-25,27-29,37-41], eight studies highlighted the contribution of RTIs to trauma-related injuries [26,31-36], and 11 studies described the anatomical distribution of injuries sustained in a road crash [23-26,28,31$34,36,37]$. While 11 studies provided information on exposures such as alcohol, seatbelt use and vehicle type [23-25,27,28,30,37-41], only two studies, published in 1991 and 1996 [40,41], incorporated epidemiological designs that enabled identification of aetiological factors for RTIs.

\section{Appraisal of study methods and quality}

Although the majority of studies were case series, there was wide variation in study design and quality. Most of the studies conducted outside PNG were small except for one study in Fiji reviewing national road crash data $(\mathrm{n}=2277)$ [37]. In general, PNG studies involved larger study samples (up to 5772) including three ecological studies drawing on the national road crash database [38-40].

The methodological quality of the studies or the ability to appraise this was compromised by inadequate reporting of population characteristics, case definitions, recruitment methodology (source, eligible and study population), exclusion criteria, data collection and analysis, response rates, and identification of potential biases and confounders. Most research designs failed to consider possible biases in analysis and the interpretation of findings. Since many studies reviewed post mortem records, potential cases may have been excluded if they had not presented to the hospital setting. The majority of studies were retrospective, and the quality of data sources, (e.g. completeness, accuracy) was unspecified.
This makes it difficult to ascertain the extent to which misclassification and underreporting may have been a source of information and recall bias. No studies reported whether outcome measures or blood alcohol concentration (BAC) measurements were assessed blind to exposure information, nor whether measurement bias was considered when estimating alcohol concentration from breath or blood samples.

Regarding measures of occurrence and effect, most of the studies reported unadjusted event counts and proportions, with only three studies providing populationbased rates $[23,38,40]$, and an ecological study reporting effect estimates [40].

Acknowledging these limitations, Table 1 summarises studies investigating the burden and aetiological factors for RTIs in Pacific countries, all of which were published more than a decade ago. The key aspects of these are described next.

\section{RTI-related fatalities in PNG}

In a study of 1,279 post mortems from all causes of deaths in all ages conducted at Port Morseby General Hospital (PMGH) for the years 1962 to 1989, RTIs $(\mathrm{n}=573)$ accounted for $45 \%$ of all deaths, $75 \%$ of whom were male [29]. Another post mortem study focusing only on traumarelated fatalities in all ages $(n=608)$ at PMGH (1976 to 1985), showed that RTIs were responsible for $60 \%$ of these deaths, $83 \%$ of whom were male [28]. Notable findings in other studies included the high proportion of road deaths that occurred at the crash site or before arrival to PMGH (66\%) [24] and Goroka Hospital (81\%) [25], as well as the disproportionately high number of fatal crashes on weekends and during early morning hours $[23,28]$.

Motor vehicle passengers (46-51\%) and pedestrians (34-36\%) were the road user groups commonly involved in fatal crashes [38-40]. Head injuries were reported as the commonest cause of RTI related deaths, with in-country differences observed between Port Moresby (43\%) [28] and Goroka (71\%) [25]. In a study of 305 trauma related post mortems undertaken in PMGH, chest injuries were found to be more common among drivers (65\%) whereas in passengers, head injuries were more common (71\%) [24].

\section{RTI-related hospital admissions in PNG}

Studies suggest RTIs were responsible for $14-30 \%$ of trauma admissions [32,34], 49\% of head injury admissions [33], 10\% of abdominal trauma admissions [36], and $34 \%$ of trauma-related spinal cord injury hospital admissions [26]. The average length of stay was usually longer for RTIs compared to other trauma-related injuries with variations between hospitals (Mendi $=10$ days, $\mathrm{PMGH}=26$ days) $[32,34]$. 


\section{Table 1 Study descriptions}

\section{Study design}

1. Wyatt [23] (1980), PNG

Case series Retrospective

21 RTI-related forensic

autopsies PMGH, 1975-78.

305 trauma-related forensic autopsies, (171 RTI-related)

2. Sinha et al [24]. (1981), PMGH, 1976-80.

353 forensic autopsies

(97 RTI-related) Gorok

hospital, 1978-82.

36 trauma-related spina cord injury admissions

PMGH, Lae, and Madang hospitals, 1978-81.

5. Lourie et al [27]. (1983), PNG, 209 RTI-related admissions Case series Prospective A\&E PMGH, 1982-83.
Road user type,

injury distribution,

day and time, BAC.

\section{Key findings relevant to review}

Drivers 21\%, passengers 38\%, pedestrian

$41 \%$, males $85 \%$, males $20-39$ years $66 \%$.

Injuries: brain 25\%, spinal cord 6\%,

multiple sites 54\%. Driver fatality per

10,000 vehicles: cars (4.6), motorcycle

(21.3). Pedestrian $20 \%$ aged $<10$ years,

passengers $25 \%$ fell/jumped from moving

vehicle. Alcohol associated with $76 \%$ of

those aged $>10$ years. BAC $>80 \mathrm{mg} / \mathrm{d}$

observed in 1/3 drivers and $69 \%$ male

pedestrians, BAC> $120 \mathrm{mg} / \mathrm{dl} 62 \%$

fatalities. $46 \%$ of fatalities occurred

on Friday and Saturday

Road user type, age, sex, injury

distribution, day

and time, risk factors

$B A C$.

Drivers $17 \%$, passengers $46 \%$, pedestrians $36 \%$, males $86 \%$, $82 \%<35$ years

Injuries: head $65 \%$, chest $51 \%$, abdomen

$37 \%$, spine $18 \%$, fracture skull $57 \%$, brain

injury 53\%, and fracture ribs 39\%. Chest

injuries higher in drivers (65\%), head injuries

higher in passengers (71\%). Risk factors:

driver lost control $60 \%$, passengers fell off

a truck $60 \%$. Alcohol associated with

$85 \%$ of drivers and $90 \%$ of adult pedestrians.

$53 \%$ BAC >80 mg/dl. 57\% occurred over

weekend, $44 \%$ occurred between $6 \mathrm{pm}$

and $6 \mathrm{am}$. $66 \%$ died at the crash site

or soon after.

Injury cause,

distribution

Dead on arrival to hospital $81 \%(n=79)$

head injuries $71 \%(n=56)$, most deaths

followed ejection or jumping from a

moving vehicle. Of those who died during

hospital admission, $61 \%$ had head injuries.

Age, sex

RTI-related spinal cord injuries 34\% $(n=12)$.

For all trauma related spinal cord injuries:

$88 \%$ Male, mean age 26 years

Road user and

vehicle type,

passenger seating

seatbelt use
Drivers $15 \%$, passengers $72 \%$, pedestrians

$13 \%$, males $82 \%$, those aged $>16$ years

$87 \%, 3$ dead on arrival, $22 \%$ admitted

$40 \%$ drivers/front seat occupants injured, 13\%

front-seat occupants wore seatbelt. $28 \%$

passengers on the back of utility trucks, and

all injured. Vehicles: cars 33\%, utility trucks

$27 \%, 1 / 3$ vehicles no seat belts fitted.
Study appraisal/Comments

Method to identify eligible

cases not stated. Measurement

bias reported for incomplete or

delayed blood alcohol testing.

Post mortem records supplemented with hospital admission notes.

Incomplete records excluded,

measurement bias reported for incomplete or delayed blood alcohol testing. Comparison between RTI and non-RTI related deaths limited to those with spleen injury.

Method to identify eligible cases not stated

Incomplete information in case records reported. Selection bias not reported.

Presence of investigator blinding of outcome not stated.

Limitations of study such as selection and recall bias, well described, Measurement bias for alcohol association reported.

While risk factors for RT

identified, study design

precluded quantification of risk. 
Table 1 Study descriptions (Continued)

6. Sinha et al [28]. (1989), PNG,

Case series Retrospective
9. Maharaj [31] (1996), Fiji, Case series Retrospective

10. Mathew et al [32]. (1996), PNG Case series Retrospective

11. Liko et al [33]. (1996), PNG, Case series Prospective $(x 2)$ Retrospective (x1)

12. Watters et al [34]. (1996), PNG, Case series (x4) Prospective (x2) Retrospective (x1) Prospective and Retrospective (x1)
363 RTI-related forensic Total trauma-related

autopsies $608,60 \%$

RTI related.

573 RTI-related forensic autopsies PMGH, 1962-89 Total autopsies 1279, 45\% RTI-related

188 RTI-related admissions A\&E PMGH, 1990. Total road traffic crashes 104. autopsies PMGH, 1976-85.

Road user type,

age, sex, BAC,

injury distribution,

day and time, if

death occurred

before arrival to

hospital.

Road user

type, sex.

Road user

type, age, sex,

time and day of

crash, association

with alcohol.

140 spinal cord injury

admissions Fiji medical

rehabilitation

unit, 1985-94.

454 trauma-related

admissions Mend

hospital, 1993

274 head injury admissions

PMGH and Goroka

hospital, 1984-93.

667 trauma-related admissions

A\&E, PMGH, (35 days over

3 months); 154 trauma

admissions PMGH general

surgical unit (over 1 year);

88 trauma-related deat

prior to admission to
PMGH(8 months); 50 death

Sex, distribution of injuries.

njury distribution length of hospital stay.

Injury distribution.

Injury cause, of hospital stay.
Drivers $18 \%$, passengers $45 \%$, pedestrians

$34 \%$, males $83 \%$, $15-44$ years $70 \%$ Injuries to

the head $43 \%$, chest $30 \%$, abdomen $8 \%$,

spine and pelvis 10\%, fracture skull 15\%,

brain injury $17 \%$, intracranial bleed

$10 \%$, fracture ribs $14 \%$. Raised BAC

(> $80 \mathrm{mg} / \mathrm{dl}$ ) in $48 \%$ of drivers tested

$(n=16 / 33)$, and $67 \%$ of pedestrian

( $n=20 / 30) 54 \%$ occurred over the

weekend, $40 \% 6 \mathrm{pm}$ to $6 \mathrm{am} \mathrm{2/3}$

died at the crash site or soon after

$75 \%$ males $(n=432)$. Total males: drivers

$12 \%$, passengers $35 \%$, pedestrians $28 \%$

Annual crude data shows increasing

RTI-related fatality trends over

4 decades

$74 \%$ males $(n=136), 48 \%$ aged $18-29$ years. $49 \%$ of road traffic crashes associated with alcohol. Most crashes occur in first part of day, but for alcohol related crashes, more common at night and early morning. Also alcohol related crashes more common on weekends. Road users - $25 \%$ drivers, $61 \%$ passengers. For those admitted to hospital, $43 \%$ drivers, $54 \%$ of passengers and $31 \%$ of pedestrians.

Trauma-related spinal cord injuries 54\% $(n=75), 25 \%$ RTI related $(n=19)$ Fijian males comprised $87 \%$ of trauma-related spinal cord injuries.

RTI related trauma admissions $14 \%(n=63)$ Injuries to head $37 \%$ with 2 deaths, chest $14 \%$, abdomen $6 \%$, fractures and dislocations $29 \%$, Average length of stay for RTI, 9.6 days, median 5 days, range 1-51 days, same for assaults

RTI related head injuries 49\% $(n=134)$. Distribution of admissions, 55\% to PMGH and $45 \%$ to Goroka hospital Head injury case fatality $21 \%$ distribution, length

RTI A\&E admissions 6\%, hospital admission $30 \%$ Mean stay for RTI, 26 days, twice as long compared to assault accidents and sports Deaths prior to admission RTI $30 \%$ $(n=26)$, assault $45 \%(n=40)$. Total head injuries $37 \%(n=33)$, RTI related $n=24$.
Reports on five year extension to earlier study by Sinha et al [28] Measurement bias reported for incomplete or delayed blood alcohol testing.

Limited reporting on methodology. Bias due to incomplete datasets, identified.

Data source; administered questionnaire, clinical assessment, and autopsy reports. Validation of definition of alcohol-related road traffic crash and assessment of alcohol intoxication not stated. Presence of investigator blinding of outcome not stated.

Included both trauma and nontrauma-related spinal cord injuries. Results reported as event counts and proportions.

Methods of data collection not reported. Exclusion of 15\% of patient charts due to incomplete data.

Method to identify eligible cases not reported. Selection bias not reported.

Four studies over a period of time. Recruitment dates for trauma-related admissions randomised. Method to identify eligible cases as well as selection bias not reported. 
Table 1 Study descriptions (Continued)

during admission (over

13. Ravia [35] (1999), Yap, Case series Retrospective

14. Ponifasio [36] (2001), PNG, Case series Prospective

15. Prasad et al [37]. (1981), Fiji Case series - hospital and

population-based Retrospective

100 injury-related admissions A\&E Yap State

Hospital,1996-98

213 abdominal trauma related admissions to PMGH (Feb 1992- Jun 1994), and 98 to Lae hospital, 1996

2277 road traffic crashes Fiji, 1980; 872 road traffic crashes Western division province Fiji, 1980; 165 RTl-related admissions Lautoka hospital, 1980.

16. Jayasuria [38] (1991), PNG Ecological study Retrospective

3202 motor vehicle crashrelated injury registrations
Road user type, association with alcohol, residence

Distribution of injuries

Road user type, age, sex, ethnic group, injury distribution, day factors. (314 deaths), Royal PNG Constabulary database for traffic accidents, 1987; National statistical office data for motor vehicle crash-related injury trends prior to 1980. Motor vehicle registry, and Licensed drivers National statistical office injuries/deaths by road user and vehicle type, age, time of crash
Drivers 12, passengers 2, pedestrians 0 , RTI-related injury admissions 14\% ( $n=14)$. Five times increase in RTI among drivers from $n=2$ to $n=10$. $88 \%$ of all injuries associated with alcohol

RTI-related non-fatal abdominal injuries 10\% $(n=30), 311$ admissions: 214 males aged 13-56 years, mean 22 years.

Road traffic crashes: Fiji 1\%, WD 6\%. WD $9 \%$ of road crash victims required hospital admission. Risk factors: dangerous driving (66-70\%): pedestrian fault (7.5\%): alcohol (4\%); speed (2.2-2.5\%); mechanical defects. Most crashes occurred during the day and in dry weather conditions, $75-77 \%$ crashes occurred on tar-sealed roads. Hospital admissions: 73\% male, 24\% aged $20-29$ years, 60\% Fiji-Indian, 32\% Fijian, 40-46\% head and neck injuries. Crashes increased during school holidays, over weekend, afternoons and evenings. Children more likely to be injured as pedestrians. Falling off the back of utility vans common.

Motorisation, crashes, Injuries and deaths: drivers 18\%, passengers $61 \%$, ped 61\%, pedestrians 19\%, 23\% 26-30 years. Deaths: Drivers $13 \%$, passengers $51 \%$ pedestrians 34\%. Trends in injuries and death by road user type have not changed much since 1970. However, for pedestrians the fatality index (deaths/deaths and injuries) there was a significant increase from $11 \%$ to $18 \%$ for the period 1970 to 1987 . Rate of pedestrian injury per 100000 population $=31$ (21-30 years) 20 ( $0-10$ years), and 18 (30-50 years). Total deaths and injuries by vehicle type: $44 \%$ utility - small pick-up trucks), 16\% heavy goods vehicles - single unit trucks, 18\% pedestrians, $10 \%$ cars. Pedestrians, 32\% aged $<10$ years. Crash rates by vehicle type (1982-87), declining, but buses increasing to four times the rate of cars and 2.4 times that of utility vehicles. Severity of crash and vehicle type (1987); highest rates of injury and fatality: drivers highest rates of injury and fatality: drivers
(motorcycles), passengers (utility, heavy goods (motorcycles), passengers (utility, heavy go
vehicles, buses). Increased crashes from
Methodology section limited. Biases not reported.

Method of data collection and biases not reported.

Limited reporting on methodology and quality of data. Risk factors indicated, but study design precluded quantification of risk. No biases reported.

Data collection, exclusion criteria, not reported. Results reported as trends in unadjusted event counts, proportions, and rates. 
6 pm, and over weekends (Friday and

Saturday)

17. Hills et al [39]. (1993), PNG, Ecological study Retrospective

4485 motor vehicle crashesrelated injury registrations, Royal PNG Constabulary database for traffic accidents, 1991. Other LMIC countries: Bandung $\mathrm{n}=1059$, (1990) Malaysia $n=37955$, (1992) Malaysia n=37955, (1) Colombo $n=946$ (1991-92) Total crashes 45702.

18. Nelson et al [40]. (1991), PNG, Ecological study Retrospective

5772 motor vehicle crashesrelated injury registrations

(1921 deaths), Royal PNG Constabulary database for traffic accidents, 1984 Motor vehicle registry and Licensed drivers National statistical office, 1980-84; Traffic survey 1984 on vehicle occupancy.

Road user type, Vehicle type, ownership and occupancy characteristics Crash severity and crash rates ge, vehicle typ ollision characteristics, day and time of crash.
Pedestrians ranked 1st or 2nd for RTIs Peak age for RTIs: 21-30 years (PNG, Karachi, Colombo); 16-25 years (Malaysia, Bandung) Pedestrians: 6-10 years peak for PNG and Malaysia. Vehicle type: utility trucks - PNG $45 \%$, other LMIC countries - mostly motorcycles. Vehicle collisions: PNG - rollover, Malaysia side or $90^{\circ}$, Bandung collisions with pedestrians. Number of vehicles in collision: PNG > 70\% single vehicle. Most injuries occurred in rural areas (70\%), associated with higher speed, and delayed medical aid. Common day and time for RTIs, PNG - Friday and Saturday, usually alcohol-related;

between 8 am to $8 \mathrm{pm}$.

Fatalities: drivers 17\%, passengers 46\%, pedestrian $36 \%$. Utility responsible for 38\% of crashes, $65 \%$ passenger fatalities. 34\% crashes involve single vehicles, RR of fatality; Driver - utility 0.99 , bus 0.88 , car 1.57; Passenger: utility 3.1 , bus 2.4, car 1.3. RR of crash involvement; utility 1.07, bus 2.14, car 0.87. Open back vehicles responsible for high number of fatalities per crash occupants thrown out of vehicle. Potential $27 \%$ reduction in crash fatalities if utility and heavy goods vehicles restricted to designed passenger occupancy

Methodology for data collection not reported. Results reported as unadjusted proportions comparing countries. Identified variation in defining injury severity.

97\% males, 98\% PNG Nationals, BAC > 80 mg/d 24\% Males, 21\% Females, 24\% drivers. (Driver BAC > $150 \mathrm{mg} / \mathrm{dl} 12 \%, \mathrm{BAC}>215 \mathrm{mg} / \mathrm{d} / 4 \%$ : Friday night early Saturday morning 29\% drivers BAC $>80 \mathrm{mg} / \mathrm{dl}$, Thursday 27\%, Saturday 25\%, Sunday $8 \%$. BAC $>80 \mathrm{mg} / \mathrm{dl} 17 \%$ after 22 cases excluded. BAC $>80 \mathrm{mg} / \mathrm{dl}$ PNG nationals (citizens) 22\% Non-PNG nationals 33\% sampling error significant $(p<.05)$

Drivers $27 \%$, passengers $62 \%$, pedestrians $11 \%$. 2 fatalities, $2 \%$ hospitalised, $76 \%$ discharged.
Methodology for data collection, exclusion criteria, not reported. Results reported as trends in unadjusted event counts, proportions, and rates, for motorisation, crashes, deaths and injuries stratified by road user, vehicle type, age and time of crash. Reported limitations to notification, collection, assumptions, and modelling - eg multiple vehicle crashes reported as total injuries per event therefore unable to identify vehicle with casualties. Effect estimates identify RR for drivers and passengers based on type of vehicle.

Non-randomised sampling by site, day, time. No nor vehicle type. 22 participants excluded due to test conducted $<20$ minutes from the last drink. Measurement bias for BAC not reported. methodology and response rate provided

Little information on 
Table 1 Study descriptions (Continued)

BAC tests, 11 pm to 3 am,

for 15 weekends (1990).
Road user type,

$\mathrm{BAC}$ and breath

alcohol concentration.
BAC $>80 \mathrm{mg} / \mathrm{dl}$ in $50 \%$ of A\&E admissions,

and 8 drivers $(n=8)$ distribution of blood

and breath alcohol

concentration results

among cases. Results

reported as events with

no adjustment for

confounding and bias,

including differences in

testing methods. 


\section{RTI-related studies in pacific countries other than PNG}

RTIs contributed to $14 \%$ of injury related admissions $(\mathrm{n}=100)$ to the accident and emergency (A\&E) department in Yap hospital [35], and 25\% of trauma-related spinal cord injury admissions $(n=75)$ to a rehabilitation unit in Fiji [31]. A Fiji study examining national $(\mathrm{n}=2277)$ and Western Division) Province $(\mathrm{n}=872)$ data reported deaths in $1 \%$ and $6 \%$ of crashes respectively [37]. In this study, $40 \%$ of those hospitalised had sustained head and neck injuries, while injured children were more likely to be pedestrians [37].

\section{Potential contributors to RTIs}

Although we did not identify any aetiological studies with appropriate control (unexposed) groups, several studies suggested factors that were likely to be important contributory factors to road crashes.

An ecological study drew attention to vehicle type, noting increased risks of crashes involving buses and open-back utility vehicles compared with cars [40]. Several other studies also noted the high proportion of utility vehicles involved in crashes [27,38,39]. When combined with road user type, passenger fatalities were noted to be highest for utility vehicles and lower for buses and cars [40]. Between 25 and $60 \%$ of passenger deaths were due to falls from utility vehicles [23,25], attributed largely to vehicle overcrowding [40].

In contrast to passenger injuries, driver injuries were reported to be highest for cars, with some studies attributing up to $70 \%$ of RTI fatalities to driver error [24,37]. One review of 121 post mortem records in PNG identified that motorcycle drivers were five times more likely to die in a road crash than car drivers [23].

Several studies commented on the role of alcohol in RTIs. In a roadside survey of motor vehicle drivers $(\mathrm{n}=893)$, and review of RTI related drivers assessed at the PMGH emergency department $(n=10)$, BAC levels above $80 \mathrm{mg} / \mathrm{dL}$ were detected in $24 \%$ and $80 \%$ of drivers, respectively [41]. Post mortem data on traumarelated cases revealed BAC levels greater than $80 \mathrm{mg} / \mathrm{dl}$ in $48 \%$ of drivers and $67 \%$ of pedestrians [28]. In 188 RTI-related patients involved in 109 crashes, 49\% of crashes were associated with alcohol [30]. Several studies suggested that alcohol-related crashes were more common at night, early morning, and during weekends $[23,28,30,41]$. While not designed as a formal aetiological investigation, one study in Fiji attributed $4 \%$ of road crashes to alcohol and $2.5 \%$ to speed [37].

\section{Discussion}

The literature regarding the burden and risk factors in the Pacific region remains largely limited to descriptive studies in PNG with important limitations in their ability to examine the population-based burden of road crashes and investigate related risk factors. No RTI focused epidemiological studies have been published for over 15 years and few were conducted outside PNG. Notwithstanding these limitations, the published literature indicates that road crashes are a major public health problem. Studies from PNG reported that RTIs contributed to at least $40 \%$ of all deaths, $60 \%$ of trauma-related deaths, one third of trauma-related hospitalisations, and $40 \%$ of all head injuries. Most (two thirds) RTI-related deaths occurred prior to hospitalisation with related fatalities particularly high among pedestrians and passengers. Although head injuries were the most commonly reported RTI-related injury, chest injuries were reported to be particularly common among motor vehicle drivers. The available literature suggests that vehicle type (openback utility), utility vehicle overloading, and alcohol are potentially important risk factors for RTI.

This review was limited to scientific publications and the English language. Therefore, it excluded the grey literature and routinely collected data such as police annual reports and national hospital and mortality statistics, most of which report events but provide little critique or analysis. The diverse methodological characteristics of the studies identified made it inappropriate to undertake a metaanalysis, or infer that the findings from these largely PNG focused studies can be generalised to Pacific countries more generally.

Nevertheless, this review adds to the evidence base of previous reviews on RTI in less resourced settings $[7,43,44]$, focusing in this case, on Pacific countries which are often absent or overwhelmed by statistics from countries with very large populations in the Western Pacific region. A defining feature of this review is the paucity of robust and contemporary epidemiological RTI studies from Pacific countries, suggesting research attention to RTIs in the region have not been a priority $[45,46]$ and long overdue. However, the evidence available indicates that, as in other less resourced settings, RTIs contribute significantly to the burden of RTIs in Pacific countries and poor data should not delay action [47],

The review particularly reveals the need to undertake well-designed aetiological studies that can quantify the contribution of important context-specific risk factors associated with serious road crashes. Indicative findings from the review suggest a key area requiring focused attention in PNG is improved safety considerations relating to the use of utility type vehicles [48]. While the approaches to address this must take into account the socio-economic and transportation implications for the communities involved [49,50], it has been argued that restricting passenger numbers through vehicle occupancy capacity limits may have the potential to reduce crash fatalities by almost 30\% [40]. Other areas amenable to well-implemented legislative interventions in the 
region include the use of seatbelts [51] and deterrents to drink driving [16]. Given the high proportion of road deaths at the crash scene, greater attention is required to health system improvements including pre-hospital care and the training of first responders [2].

The World Report on road traffic injury prevention identifies the need for a comprehensive multi-sectoral, integrated, systems approach that focuses on improved information systems, institutional capacity strengthening, research that quantifies common modifiable risks, and resources for targeting these [2]. Reliable and sustainable injury data surveillance [52-55] including secondary data routinely collected from hospital and police records, comprises an important foundation for monitoring and evaluating road safety strategies in the Pacific context $[19,39]$. This would be strengthened by the standardisation of RTI case definitions, data collection processes, analysis and reporting from surveillance systems [56], while ensuring dissemination approaches link findings to interventions, policies, context-specific research and funding mechanisms. As noted elsewhere [57], a critical requirement for identifying and implementing effective road safety strategies is a skilled workforce integrated across relevant stakeholder agencies including legislation, economic policy, capital infrastructure, road engineering, vehicle design, and health care.

\section{Conclusions}

This review found that the burden of road traffic injuries in PNG and other less resourced Pacific countries is significant, however, the contribution of modifiable risks for RTI remain poorly quantified. While some studies revealed the likely importance of factors such as alcohol misuse and vehicle type, effective public health and road safety policy requires attention to population-based studies that can identify and quantify the contributors to RTI in the Pacific context. Improving the quality of secondary data sources from routinely collected hospital and police surveillance systems is essential.

\section{Additional files}

Additional file 1: Search string applied for the review.

Additional file 2: PRISMA checklist for systematic reviews [58].

\section{Abbreviations}

A\&E: Accident and emergency; BAC: Blood alcohol concentration; PNG: Papua New Guinea; PMGH: Port Moresby General Hospital; RTI: Road traffic injuries.

\section{Competing interests}

The authors declare that they have no competing interests.

\section{Authors' contributions}

$\mathrm{JH}$ conducted the literature search, selected included papers, critically appraised the papers, developed the evidence tables, and wrote the initial draft of the paper. SA and RJ contributed substantially to the design of the evidence tables, the outline of the paper, interpretation of findings and writing the paper. All authors read and approved the final manuscript.

\section{Acknowledgements}

This study was funded by an international collaborative grant from the Wellcome Trust (UK) and the New Zealand Health Research Council.

Received: 1 December 2011 Accepted: 30 April 2012

Published: 25 June 2012

\section{References}

1. Mathers CD, Loncar D: Projections of global mortality and burden of disease from 2002 to 2030. PLoS Med 2006, 3(11):e442

2. Peden M, Scurfiled R, Sleet D, Mohan D, Hyder AA, Jarawan E, Mathers C: World report on road traffic injury prevention. Geneva: World Health Organization; 2004.

3. Ameratunga S, Hijar M, Norton R: Road-traffic injuries: confronting disparities to address a global-health problem. Lancet 2006, 367(9521):1533-1540.

4. World Health Organization: Global Status Report on Road Safety: time for action. Geneva: World Health Organization; 2009.

5. Loison G, Bourre AL, Malo C, Tamson R: The health implications of urbanisation in the South Pacific. Journal de la Société des océanistes 1974, 30(42-43):79-104.

6. Taylor $\mathrm{R}$, Thoma K: Mortality patterns in the modernized Pacific Island nation of Nauru. Am J Public Health 1985, 75(2):149-155.

7. Odero W, Garner P, Zwi A: Road traffic injuries in developing countries: a comprehensive review of epidemiological studies. Trop Med Int Health 1997, 2(5):445-460.

8. Barker JC: On the road to health? Road Traffic Accidents in Pacific Societies: The case of Niue Islands, Western Polynesia. Am J Hum Biol 1993, 5:61-73.

9. Penington A: Road accidents and alcohol. Fiji Med J 1978, 6(8):196-199.

10. Bouraga P: Road traffic accidents and the role of the police. PNG Med J 1980, 23(2):59.

11. Shepherd A: Road traffic accidents - a view from the highlands. PNG MED J 1980, 23(2):57-58.

12. Lourie JA: Use of seat-belts in Port Moresby. PNG MED J 1982, 25(4):214-218

13. Scrimgeour EM: Drinking and driving in Papua New Guinea. Med J Aust 1983, 1(13):622.

14. Paksoy N: Problems in paradise: pattern of coroner's autopsies in Western Samoa. Med J Aust 1990, 152(11):612

15. Sapak P, Mea V: Driving practices in the National Capital district, Papua New Guinea. Pacific Health Dialog 1996, 3(1):25-27.

16. World Health Organization: Road safety in the Western Pacific region: call for action. Geneva: World Health Organization; 2009.

17. Parker N: Psychosomatics of accidents. PNG MED J 1980, 23(1):21-25.

18. Sengupta SK, Patil NG, Law G: Seat-belt message and the law? PNG MED J 1989, 32(3):199-202

19. Hills BL, Thompson NM, Kila K: Accident reduction research in Papua New Guinea, 19th Transport Highways and Planning Summer Annual Meeting Proceedings of Seminar C University of Sussex, 9-13 September, 1991. London: Transport Research Laboratory; 1991:65.

20. The World Bank: How we classify countries. http://data.worldbank.org/about/ country-classifications. Accessed 01 October, 2010.

21. Sackett DL, Straus SE, Richardson WS, Rosenburg W, Haynes RB: EvidenceBased Medicine. Edinburgh: Churchill Livingstone; 2000.

22. Effective Practice, Informatics and Quality Improvement. http://www.fmhs. auckland.ac.nz/soph/depts/epi/epiq/ebp.aspx.

23. Wyatt GB: The epidemiology of road accidents in Papua New Guinea. PNG MED J 1980, 23(2):60-65.

24. Sinha SN, Sengupta SK, Purohit RC: A five year review of deaths following trauma. PNG MED J 1981, 24(4):222-228.

25. Palmer P: Autopsies at Goroka hospital from 1978-1982: a review. PNG MED J 1982, 25(3):166-167.

26. Gee RW, Sinha SN: The epidemiology of spinal cord injuries in Papua New Guinea. PNG MED J 1982, 25(2):97-99.

27. Lourie J, Sinha S: Port Moresby road traffic accident survey. PNG MED $J$ 1983, 26(3-4):186-189. 
28. Sinha SN, Sengupta SK: Road traffic accident fatalities in Port Moresby: a ten-year survey. Accid Anal Prev 1989, 21(3):297-301.

29. Cooke RA, Wilkey IS, Aiken GH, Murthy P, Sengupta K: Forensic pathology in Papua New Guinea 1962-1989. Med J Aust 1992, 157(11-12):826-828.

30. Posanau CS: Alcohol and motor vehicle accidents in the National Capital District of Papua New Guinea. Medicine and Law 1994, 13(5-6):399-406.

31. Maharaj JC: Epidemiology of spinal cord paralysis in Fiji: 1985-1994. Spinal Cord 1996, 34(9):549-559.

32. Matthew PK, Kapua F, Soaki PJ, Watters DA: Trauma admissions in the southern highlands of Papua New Guinea. Aust N Z J Surg 1996, 66(10):659-663.

33. Liko O, Chalau P, Rosenfeld JV, Watters DA: Head injuries in Papua New Guinea. PNG MED J 1996, 39(2):100-104

34. Watters DA, Dyke TD, Maihua J: The trauma burden in Port Moresby. PNG MED J 1996, 39(2):93-99.

35. Ravia AA: Alcohol related injuries in Yap. Pacific Health Dialog 1999, 6(1):52-56.

36. Ponifasio P, Poki HO, Watters DA: Abdominal trauma in urban Papua New Guinea. PNG MED J 2001, 44(1-2):36-42.

37. Prasad J, Mar SW: Road traffic accidents in the Western Division. Fiji Med J 1981, 9(8/9):129-133.

38. Jayasuriya R: Trends in the epidemiology of injuries due to road traffic accidents in Papua New Guinea. Asia-Pacific J Pub Health 1991, 5(1):41-48.

39. Hills B, Baguely CJ: Accident data collection and analysis: The use of the microcomputer package MAAP in five Asian countries, Proceedings of the Asian Road Safety Conference, Kuala Lumpur, Malaysia, 25-28 October 1993. London: Transport Research Laboratory; 1993:16.

40. Nelson DC, Strueber JV: The effect of open-back vehicles on casualty rates: the case of Papua New Guinea. Accid Anal Prev 1991, 23(2-3):109-117.

41. Hills BL, Thompson N, Johnson AF, Posanau CS: A roadside and hospital survey of drinking and driving in Port Moresby, Papua New Guinea, International Conference on Asian Road Safety, Beijing, 29-31 October 1996. London: Transport Research Laboratory; 1996:7.

42. Attah Johnson FY, Hills B, Posanau CS: Roadside driver alcohol survey and hospital alcohol survey in Port Moresby, Papua New Guinea. Med Law 1995, 14(3-4):157-161.

43. Odero WO, Zwi AB: Alcohol-Related Traffic Injuries and Fatalities in Developing Countries, Shaffer Library of Drug Policy.

44. Ryan GA: Alcohol and Road Traffic Crashes in the Western Pacific Region. In: Shaffer Library of Drug Policy; 1993.

45. Reeder JC: Papua New Guinea: targeting research to things that matter. Med J Aust 2004, 181(11-12):610-611.

46. Naraqi S, Feling B, Leeder SR: Disease and death in Papua New Guinea. Med J Aust 2003, 178(1):7-8.

47. Peden M, Toroyan T: Counting road traffic deaths and injuries: poor data should not detract from doing something! Ann Emerg Med 2005, 46(2):158-160

48. Desapriya E, Subzwari S, Sasges D, Basic A, Alidina A, Turcotte K, Pike I: Do light truck vehicles (LTV) impose greater risk of pedestrian injury than passenger cars? A meta-analysis and systematic review. Traffic Injury Prevention 2010, 11(1):48-56.

49. Mohan D: Road safety in less-motorized environments: future concerns. Int J Epidemiol 2002, 31(3):527-532.

50. Forjuoh SN: Traffic-related injury prevention interventions for lowincome countries. Inj Control Saf Promot 2003, 10(1-2):109-118.

51. Benjamin AL: The use of seatbelts in Port Moresby 12 years after the seatbelt legislation in Papua New Guinea. PNG MED J 2007, 50(3-4):152-156

52. Wainiqolo I, Kafoa B, McCaig E, Kool B, Mclntyre R, Ameratunga S: Development and piloting of the Fiji Injury Surveillance in Hospitals System (TRIP Project-1). Injury 2011, http://www.ncbi.n/m.nih.gov/pubmed/ 22098715. Accessed Nov 16.

53. Shamim S, Razzak JA, Jooma R, Khan U: Initial results of Pakistan's first road traffic injury surveillance project. Int J Inj Contr Saf Promot 2011, 18(3):213-217

54. Rojas Medina Y, Espitia-Hardeman V, Dellinger AM, Loayza M, Leiva R, Cisneros G: A road traffic injury surveillance system using combined data sources in Peru. Rev Panam Salud Publica 2011, 29(3):191-197.
55. Graitcer PL: Injury surveillance in developing countries. MMWR CDC Surveill Summ 1992, 41(1):15-20.

56. Ozanne-Smith J, Bartolomeos K, Grills N: WHO to develop guide to promote standardised documentation of deaths due to injuries and violence. Inj Prev 2009, 15(6):431.

57. Mock C, Kobusingye O, le Anh V, Afukaar F, Arreola-Risa C: Human resources for the control of road traffic injury. Bull World Health Organ 2005, 83(4):294-300.

58. Moher D, Liberati A, Tetzlaff J, Altman DG, The PRISMA Group: Preferred Reporting Items for Systematic Reviews and Meta-Analyses: The PRISMA Statement. PLoS Med 2009, 6(6):e1000097. doi:10.1371/journal. pmed1000097.

doi:10.1186/1471-2458-12-479

Cite this article as: Herman et al:: Burden of road traffic injuries and related risk factors in low and middle-income Pacific Island countries and territories: a systematic review of the scientific literature (TRIP 5). BMC Public Health 2012 12:479.

\section{Submit your next manuscript to BioMed Central and take full advantage of:}

- Convenient online submission

- Thorough peer review

- No space constraints or color figure charges

- Immediate publication on acceptance

- Inclusion in PubMed, CAS, Scopus and Google Scholar

- Research which is freely available for redistribution

Submit your manuscript at www.biomedcentral.com/submit 